ISSN 2328-353X

\title{
Indirect Cost Of Diabetes In The Arab Region
}

A. Boutayeb ${ }^{1 *}$,W. Boutayeb ${ }^{1}$, M. E. N. Lamlilili ${ }^{1}$ S. Boutayeb ${ }^{2}$

Review Article

${ }^{1 *}$ LaMSD, URAC04, Faculty of Sciences, University Mohamed Ier, Oujda, Morocco.

2 Department of medical oncology, National Institute of Oncology, Rabat, Morocco.

\begin{abstract}
Diabetes is one of the chronic diseases with a high prevalence and consequently a substantial socio-economic burden in Arab countries. In this paper, we propose for the first time an estimation of the indirect economic cost of diabetes incurred by the loss of productivity caused by disability and premature mortality due to diabetes in the Arab region. The 21 countries were divided into three income groups and the indirect cost of diabetes was estimated in each group. The total indirect cost was estimated to be around USD 72 billion whereas the average per capita indirect cost was estimated to be USD 2770, varying from USD 423 in group 3 to USD 7959 in Group1. The huge indirect economic cost and the associated social burden stress the importance that health decision makers should give to sensitisation, early diagnosis and treatment of diabetes in the Arab region where the prevalence of diabetes is very high.
\end{abstract}

Key Words: Diabetes; Indirect Cost; Prevalence; Arab Countries; Productive Life Years; Disability.

\section{*Corresponding Author:}

A. Boutayeb

LaMSD, URAC04, Faculty of Sciences, University Mohamed Ier, Oujda, Morocco.

Tel: 212536 500601; Fax: 212536500603

E-mail: x.boutayeb@menara.ma

Received: October 28, 2013

Accepted: November 28, 2013

Published: November 29, 2013

Citation: A. Boutayeb, W. Boutayeb, M. E. N. Lamlili, S. Boutayeb (2013) Indirect Cost of Diabetes in the Arab Region. Int J Diabetol Vasc Dis Res. 1(4), 24-28. doi: http://dx.doi.org/10.19070/2328-353X-130005

Copyright: A. Boutayeb ${ }^{\circ}$ 2013. This is an open-access article distributed under the terms of the Creative Commons Attribution License, which permits unrestricted use, distribution and reproduction in any medium, provided the original author and source are credited.

\section{Introduction}

Once associated with economic development and considered as diseases of the rich, non-communicable diseases (NCDs) are now affecting countries worldwide, threatening particularly economic and human development of low and middle-income countries. Diabetes is one of these diseases having a high prevalence and consequently a substantial socio-economic burden in the Arab region (Boutayeb A, 2006). According to the International Diabetes Federation Report 2011, six of the top 10 countries with the highest prevalence of diabetes (in adults aged 20 to 79 years) are in the Middle East: Kuwait (21.1\%), Lebanon (20.2\%), Qatar (20.2\%), Saudi Arabia (20.0), Bahrain (19.9\%) and UAE (19.2\%) (IDF2011, Boutayeb et al 2012).

As indicated in a previous paper, diabetes raises the equity problem between and within countries (Boutayeb A and Boutayeb S 2005). Due to its chronic nature with severe complications, this disease needs costly prolonged treatment and care. Consequently, its economical burden affects individuals, households and the whole society. The American Diabetes Association estimates that the yearly cost for treating a person with diabetes is over 5 times more than for a person without diabetes (US $\$ 13,243$ vs $\$ 2560$ ). In 2007, an amount of USD174 billion was spent on diabetes (USD116 billion for medical expenditures (direct costs) and USD58 billion (indirect costs) in reduced national productivity. It is estimated that the value will be more than $\$ 350$ billion by 2025 and $\$ 2.6$ trillion in the next 30 years (ADA2008).

In 2003, Barcélo et al. (2003) carried out a study on the cost of diabetes in Latin America and the Caribbean (LAC). The 26 countries of the LAC region were classified into four groups on the basis of per capita gross national product (GNP). The loss of productivity due to permanent and non-permanent disability, and mortality related to diabetes was responsible for an indirect cost of US\$ 54.5 billion, representing $83.56 \%$ of the total cost of diabetes in LAC.

Following the study in LAC, Kirigia et al. (2009) proposed a similar study in the WHO African region. Evaluated in International dollars (PPP), the average cost per person with diabetes in groups 1,2 and 3 was estimated at $\$ 11431.6, \$ 4770.6$ and $\$ 2144.3$ respectively. The total economic loss for the whole region was $\$$ 25.51 billion (PPP). Indirect cost of diabetes accounted for $43 \%$, dominantly caused by permanent disability (88.5\%) (Kirigia et al; 2009).

A study carried out on the direct medical cost of diabetes and its complications in the Eastern District of Abu Dhabi emirate (AlAin region) estimated that the annual direct treatment costs of a diabetic patient without complications (US\$ 1605) was 3.2 times higher than the per capita expenditure for health care in the UAE (US\$ 497)(Al-Maskari 2010).

In two recent papers, we estimated the direct and indirect cost of diabetes in Morocco (Boutayeb et al; 2013a), and the direct 
cost of diabetes in the Arab region (Boutayeb et al; 2013b). The present paper is devoted to the estimation of indirect cost of diabetes in the Arab region.

\section{Methods}

Accurate estimation of diabetes prevalence is lacking in most Arab countries and reliable data on diabetes constitute a real problem. In absence of registries and precise data collected in each Arab country, extrapolations are often used by organizations like the World Health Organization (WHO) and the International Diabetes Federation (IDF).

In this study, following Barcélo et al (2003) and Kirigia et al (2009), the Arab region was divided into three income groups according to the WHO Global Health Expenditure Atlas (WHO Atlas 2012) (Table 1) and the indirect cost incurred by diabetes was estimated in each group, using all available data in each country and extrapolating for countries where data is not available by assuming that the costs are similar for different countries in the same income group.

\section{Prevalence of diabetes}

For the number of people with Type 2 diabetes, our study was based on a bibliographic research on recent studies carried out in different Arab countries in order to estimate the prevalence of diabetes mainly among adult people( 20 years and over). Our database was limited to published works based on surveys respecting the standards of statistical sampling techniques (population size, age, sex, selection criteria, etc...). In countries for which no prevalence was available, the value considered was the mean of income group to which the country belongs.

For the number of people with Type1 diabetes, lack and scarcity of reliable data was more crucial but the previous procedure was followed.

\section{Indirect cost of diabetes}

Indirect economic cost of a disease is mainly estimated by the cost of premature mortality, permanent and temporarily disability caused by this illness. It should be stressed, however, that these non-medical costs are difficult to measure. Beside the problem raised by what to include in indirect costs and how to measure and value such economic costs, overlapping and double counting that may result from indirect cost estimation constitute a subject of discussion and debate among researchers (Bjork2001). Usually, three approaches are used to estimate indirect costs of diseases: human capital, willingness-to-pay and friction costs. In this study, following Barcélo et al (2003), we use the first approach in which indirect costs of diabetes are estimated by the lifetime forgone earnings caused by premature death and disability due to diabetes.

\section{- Mortality cost}

Following the method used by Kirigia et al (2009) and using the probabilities of diabetes associated deaths in different age groups given by Murray and Lopez (1996), the number of productive years lost by people aged 15 to 60 years was estimated by subtracting the averages of age of onset and duration of diabetes from life expectancy of the country. For children and adolescents, productive years lost was calculated by subtracting the averages of age of onset and duration of diabetes plus 14 years from life expectancy of the country.

\section{- Cost of permanent disability caused by dia- betes}

Following Barcélo et al (2003), we assumed that 5\% of the total population with diabetes was permanently disabled. The estimated cost of permanent disability was calculated by multiplying the number of productive years lost to disability by the per capita GDP.

\section{- Cost of temporarily disability caused by dia- betes}

The cost of diabetes-related disability was estimated for people with diabetes aged 15 to 60 years. The cost of disability in young people (0-14) and those retired (above 60 years) was ignored. It should be stressed that, following Barcélo et al (2003) and Kirigia et al (2009), we assumed that $40 \%$ of the population with diabetes aged $<60$ years were economically active and that 60 years is the age of retirement for the majority of Arab populations.

A computer program was written, using Excel to compute all the economic costs.

\section{Results and Discussion}

The total indirect cost was estimated to be around USD 72 billion whereas the average per capita indirect cost was estimated to be

Table1: Arab countries classified according to per capita gross domestic product (GDP, USD)

\begin{tabular}{|l|l|l|}
\hline $\begin{array}{l}\text { Income group } \\
(2010)\end{array}$ & $\begin{array}{l}\text { Per capita GNP } \\
\text { (USD) }\end{array}$ & Countries \\
\hline 1 & $\begin{array}{l}>8000 \\
\text { Average: 22232 }\end{array}$ & $\begin{array}{l}\text { Bahrain(17379), Kuwait(46537), Lebanon(9262), Libya(12461), } \\
\text { Oman(20764), Qatar(82248), Saudi Arabia(15836), UAE(39619) }\end{array}$ \\
\hline 2 & $\begin{array}{l}\text { 2000-8000 } \\
\text { Average: 3109 }\end{array}$ & $\begin{array}{l}\text { Algeria(4272), Egypt(2646), Iraq(2932), Jordan(4445), Moroc- } \\
\text { co(2848), Syria(2835), Tunisia(3831) }\end{array}$ \\
\hline 3 & $\begin{array}{l}<2000 \\
\text { Average: 1181 }\end{array}$ & $\begin{array}{l}\text { Comoros(736), Djibouti(1266), Mauritania(967), Somalia(500), } \\
\text { Sudan(1328), Yemen(1219) }\end{array}$ \\
\hline
\end{tabular}


Table 2: Bibliographic review on prevalence of diabetes in Arab countries

\begin{tabular}{|l|l|l|l|l|l|}
\hline Country & Author & Publication date & population & Sample & Prevalence \\
\hline Algeria/Setif & Malek & 2001 & & & $8.2 \%$ \\
\hline Algeria/Tlemcen & Zaoui & 2007 & 20 years + & 7656 & $14.2 \%$ \\
\hline Algeria MOH & STEPS & 2003 & $25-64$ & 4000 & 7.3 \\
\hline Bahrain & Al-Mahroos & 1998 & $40-70$ & 2000 & $29.8 \%$ \\
\hline Egypt STEPS & $\begin{array}{l}\text { Ellabany } \\
\text { et al }\end{array}$ & 2005 & $15-65$ & 10000 & $15.8 \%$ \\
\hline Iraq/AlMadina & Mansour & 2008 & 20 years + & 3176 & $7.43 \%$ \\
\hline Jordan & Ajlouni & 2008 & 25 years + & & $17.1 \%$ \\
\hline Jordan & Ajlouni & 1998 & & & $3.69 \%$ \\
\hline Jordan & Jordan & 2008 & 18 years + & 3334 & $16.9 \%$ \\
\hline STEwait & Abdella & 1998 & 20 years + & 3003 & $14.8 \%$ \\
\hline Iraq MOH & STEPS & 2006 & 20 years + & 1000 & $13.5 \%$ \\
\hline Libya & Kadiki & 2001 & 20 years + & 868 & $14.1 \%$ \\
\hline Morocco & Tazi & 2000 & 20 years + & & $6.6 \%$ \\
\hline Morocco/Oujda & Ramdani & 2012 & 40 years + & 1628 & $10.2 \%$ \\
\hline Oman & Asfour & 1995 & & 5096 & $10 \%$ \\
\hline Oman & Al-Lawati & 2002 & 20 years + & 5838 & $11.5 \%$ \\
\hline Oman & Al-Moosa & 2006 & 20 years + & 7179 & U:17.7; R:10.5 \\
\hline Qatar & Bener & 2009 & 20 years + & 1117 & $16.7 \%$ \\
\hline Saudi Arabia & Al-Nuaim & 1997 & 15 years + & 13177 & UM12; UF14 RM7 ; RF8 \\
\hline Saudi Arabia & El-Hazmi & 1998 & $2-77$ years & 25337 & M:5.63 F:4.53 \\
\hline Saudi Arabia & Al-Nozha & 2004 & $30-70$ years & 16917 & 23.7 \\
\hline Saudi Arabia & $\begin{array}{l}\text { MOH- } \\
\text { WHO }\end{array}$ & 2005 & $25-64$ & 1768 & $19.2 \%$ \\
\hline Tunisia & Bouguerra & 2008 & 20 years + & 3729 & $9.9 \%$ \\
\hline UAE/Al Ain & Saadi & 2007 & 20 years + & 498 & $4.6 \%$ \\
\hline UAE & Malik & 2005 & & 5844 & $20 \%$ \\
\hline Yemen & AlHabori & 2004 & & \\
\hline & & & & & \\
\hline
\end{tabular}

USD 2770, varying from USD 423 in group 3 to USD 7959 in Group1. The indirect cost in the first group was 7 times higher than in the second group and nearly 19 times higher than in the third group. This huge variability is explained by the use of per capita income for the evaluation of lost productivity. The average indirect per capita cost of diabetes is nearly 9 times higher than the per capita health expenditure (Table3). The indirect cost of diabetes in each Arab country is given in Table Annex 1. Obviously, three parameters determine the total cost incurred indirectly by diabetes in each country: population size, diabetes prevalence and per capita GDP. Seven countries with the highest prevalence of diabetes contribute to more than $75 \%$ of the indirect cost incurred by diabetes in the Arab region.

For the 26 countries of Latin America and the Caribbean, the loss of productivity due to permanent and non permanent disability, and mortality related to diabetes was responsible for an indirect cost of USD 54.5 billion, representing $83.56 \%$ of the total cost of diabetes in LAC.

In the United States of America, it was estimated that US\$174 billion was spent on diabetes in 2007. The indirect direct cost (USD 58 billion) accounted for $1 / 3$ of the total cost incurred by diabetes (ADA2007).
According to Kirigia et al (2009), the 7.02 million cases of diabetes recorded by countries of the African Region in 2000 resulted in a total economic loss of Int $\$ 25.51$ billion with indirect cost accounting for Int $\$ 8.1$ billion(32\%) in the Region.

\section{Study Limitations and intangible costs}

In our study, we were limited by lack and scarcity of reliable data. Other limitations were related to different assumptions concerning the number of people with permanent or temporarily disability, the proportion of economically active population and the age of retirement in each Arab country.

Diabetes is a chronic disease with a high economic burden affecting rich and poor people worldwide. However, its burden goes beyond the limits of economical problems. The disease incurs also costs that are intangible and not quantifiable such as inconvenience, anxiety, pain, and more generally lower quality of life (WHO Cost). Indeed, diabetes causes more than half of all non-traumatic lower limb amputations. It is also one of the leading causes of visual impairment and blindness, and the leading cause of renal failure in many developing countries. How can we evaluate financially the loss of vision, kidneys or lower limb? And how can we estimate the affective care devoted by a family to 
Table 3: Total and per capita indirect cost of diabetes per group per year compared to per capita health expenditure

\begin{tabular}{|l|l|l|l|l|}
\hline Income group & $\begin{array}{l}\text { Indirect cost } \\
\text { (USD billion) }\end{array}$ & $\begin{array}{l}\text { Per capita indirect cost } \\
\text { (USD) }\end{array}$ & $\begin{array}{l}\text { Per capita health expenditure } \\
\text { (USD) }\end{array}$ & Ratio \\
\hline Group1 & 51.91 & 7959 & 827.5 & 9.6 \\
\hline Group2 & 19.00 & 1113 & 164.5 & 6.8 \\
\hline Group3 & 1.14 & 423 & 66.5 & 6.4 \\
\hline Total or average of 3 groups & 72.05 & 2770 & 300.3 & 8.9 \\
\hline
\end{tabular}

one of its members affected by diabetes complications? As indicated earlier, the treatment of diabetes appears not only as an economic problem but also as a sustainable development issue. For this reason, health decision makers should consider such a disease in its integrated context, requiring health education and sensitization, early diagnosis and efficient treatment to avoid complications or at least to delay them as far as possible. For instance, the budget required for sensitization, diagnosis and treatment of diabetes without complications is cost-efficient compared to the socioeconomic burden imposed by blindness, kidney failure or foot amputation.

\section{Conclusion}

Despite the limitations imposed by lack and scarcity of reliable data concerning the number of people with diabetes in the Arab countries and the large variability of prices, our study proposes for the first time an estimation of the indirect economic cost of diabetes incurred by the loss of productivity caused by disability and premature mortality due to diabetes. The huge indirect economic cost and the associated social burden stress the importance that health decision makers should give to sensitisation, early diagnosis and treatment of diabetes in the Arab region where the prevalence of diabetes is very high.

\section{JEL classifications: I11, I13, I15, J14}

\section{References}

[1]. Abdella, N., M. Al Arouj, A. Al Nakhi, A. Al Assoussi, and M. Moussa. 1998. Non-insulin-dependent diabetes in Kuwait: prevalence rates and associated risk factors. Diabetes Research and Clinical Practice 42(3): 187-196

[2]. Ajlouni, K., H. Jaddou, A. Batieha. 1998. Diabetes and impaired glucose tolerance in Jordan: prevalence and associated risk factors. J Intern Med 244: 317-23.

[3]. Ajlouni, K., Y.S, Khader, A. Batieha, H. Ajlouni, and M. El-Khateeb. 2008. An increase in prevalence of diabetes mellitus in Jordan over 10 years. Journal of Diabetes and Its Complications 22: 317-324

[4]. Al-Habori, M., M. Al-Mamari, and A. Al-Meeri. 2004. Type II diabetes Mellitus and impaired tolerance in Yemen: prevalence, associated with metabolic changes and risk factors. Diabetes Research and Clinical Practice 65: 275-281

[5]. Al-Lawati, J.A., A.M. Al Riyami, A.J. Mohammed, and P. Jousilahti. 2002. Increasing prevalence of diabetes mellitus in Oman. Diabetic Medicine 19(11): 954-957.

[6]. Al-Mahroos, F., and Mckeigue P.M. 1998. High prevalence of diabetes in Bahrainis: association with ethnicity and raised plasma cholesterol. Diabetes Care 6: 936-942

[7]. Al-Maskari, F., M. El-Sadig, and N. Nagelkerke. 2010. Assessment of the direct medical costs of diabetes mellitus and its complications in the United Arab Emirates. BMC Public Health, 10:679

[8]. Al-Moosa, S., S. Allin, N. Jemiai, J. Al-Lawati, and E. Mossialos. 2006. Diabetes and urbanization in the Omani population: an analysis of national survey data. Population Health Metrics 4:5

[9]. Al-Nuaim, AR. 1997. Prevalence of glucose intolerance in urban and rural communities in Saudi Arabia. Diabet Med 14: 595-602.

[10]. Al-Nozha, M.M., M.A. Al-Maatouq, Y.Y. Al-Mazrou, S.S. Al-Harthi, M.R. Arafah, M.Z. Khalil, et al. 2004. Diabetes mellitus in Saudi Arabia. Saudi Med J 25: 1603-10.
[11]. American Diabetes Association (ADA)(2008) Economic costs of diabetes in the U.S. in 2007. Diabetes Care 31(3): 596-615.

[12]. Asfour, M.G., A. Lambourne, A. Soliman, S. Al-Behlani, D. Al-Asfoor, A. Bold, H. Mahtab, H. King. 1995. High Prevalence of Diabetes Mellitus and Impaired Glucose Tolerance in the Sultanate of Oman: Results of the 1991 National Survey. Diabet Med 12:112-125

[13]. Barcélo, A., C. Aedo, S. Rajpathak, and S. Robles. 2003. The cost of diabetes in Latin America and the Caribbean. Bulletin of the World Health Organization 81(1):19-27

[14]. Bener, A., M., Zirie, I.M Janahi, A. Al-Hamag, M. Musallam et al. 2009. Prevalence of diagnosed and undiagnosed diabetes mellitus and its risk factors in a population based study of Qatar. Diabetes Research and Clinical Practice 84: 99-106.

[15]. Bjork, S. 2001. The cost of diabetes and diabetes care. Diabetes Research and Clinical Practice 54: S13-S18.

[16]. Bouguerra, R., H. Alberti, L.B. Salem, C.B.Rayana, J.E. Atti, S. Gaigi, C.B. Slama, B.Zouari, and K. Alberti. 2007. The global diabetes pandemic: the Tunisian experience. European Journal of Clinical Nutrition 61(2): 160-165.

[17]. Boutayeb, A. and S. Boutayeb. 2005. The burden of NCDs in developing countries. International Journal for Equity in Health 4:2

[18]. Boutayeb, A. 2006. The Double burden of communicable and non-communicable diseases in developing countries. Transactions of the Royal Society of Tropical Medicine and Hygiene 100(3):191-199.

[19]. Boutayeb, A., M. Lamlili, W. Boutayeb, A. Maamri, A. Ziyyat, and N. Ramdani. 2012. The rise of diabetes prevalence in the Arab region. Open Journal of Epidemiology 2: 55-60

[20]. Boutayeb, W., M. Lamlili, A. Boutayeb, S. Boutayeb.2013a. Estimation of direct and indirect cost of diabetes in Morocco. Journal of Biomedical Science and Engineering 3(7): 732-738

[21]. Boutayeb, A., W. Boutayeb , M. Lamlili, S. Boutayeb. 2013b. Estimation of direct cost of diabetes in the Arab region. BMC Public Health (submitted)

[22]. El-Hazmi, M.A., A. Warsy, A. Al-Swailem, A. Al-Swailem, and R. Sulaimani. 1998. Diabetes mellitus as a health problem in Saudi Arabia. East Mediterr Health J 4(1): 58-67.

[23]. Ellabany, E., and M. Abel-Nasser. 2006. Community based survey study on non communicable diseases and their risk factors, Egypt, 2005-2006, tech. rep. Egypt Ministry of Health and Population, and WHO.

[24]. International Diabetes Federation (IDF). 2011. IDF DIABETES ATLAS fifth edition. IDF, Bressels, Belgium.

[25]. Iraqi Ministry of Health. 2006. Chronic non-communicable diseases risk factor survey in Iraq, 2006, tech. rep. Iraq Ministry of Health and Ministry of planning and Development Cooperation, World Health Organization

[26]. Jordan STEPS. 2004. Survey Technical. Report. Jordan Ministry of Health and World Health Organization.

[27]. Kadiki, O.A., R.B. Roaeid. 2001. Prevalence of diabetes mellitus and impaired glucose tolerance in Benghazi Libya. Diabetes Metabolism 27(6): 647-54

[28]. Kirigia, J.M., H.B. Sambo, L.G. Sambo, and S.P. Barry. 2009. Economic burden of diabetes in the WHO African region. BMC International Health and Human Rights 9:6 http://www.biomedcentral.com/1472-698X/9/8

[29]. Malek, R., F. Belateche, S. Laoumiri et al. 2001. Prevalence du diabète de type 2 et de l'intolérance au glucose dans la région de Sétif (Algérie). Diabetes Metabolism $18: 229-253$

[30]. Malik, M., A. Bakir, B. Abi Saab, G. Roglic, and H. King. 2005. Glucose intolerance and associated factors in the multi-ethnic population of the United Arab Emirates. Diabetes Research and Clinical Practice 69:188-195

[31]. Mansour, A.A, H.L. Wanoose, I. Hani, A. Abed-Alzahrea, and H.L. Wanoose. 2008.

[32]. Diabetes screening in Basrah, Iraq: a population-based cross-sectional study. Diabetes Research and Clinical Practice 79:147-150

[33]. Ministry of Health Algeria. 2005. Algérie Enquête STEPS Technical Report. Ministry of Health Algeria and World Health Organization.

[34]. Murray, C, A.D. Lopez. 1996. Global health statistics: a compendium of incidence, prevalence and mortality estimates for over 200 conditions. World health Organization, Geneva.

[35]. Ramdani, N., J. Vanderpas, A. Boutayeb, A. Meziane, B. Hassani, J. Zoheir, A.Legssyer, M. Aziz, H. Mekhf, M. Bnouham, and A.Ziyyat. 2012. Diabe- 
tes and obesity in the eastern Morocco. Mediterranean Journal of Nutrition and Metabolism. 5:149-155.

[36]. Saadi, H, S.G. Carruthers, N. Nagelkerke, F. Al-Maskari, B. Afandi, R. Reed et al. 2007.

[37]. Prevalence of diabetes mellitus and its complications in a population-based sample in Al-Ain, United Arab Emirates. Diabetes Research and Clinical Practice 78: 369-377.

[38]. Saudi Arabia. 2005. NCD risk factors. Technical Report. Kingdom of Saudi Arabia Ministry of Health and World Health Organization

[39]. Tazi, M.A., S. Abir-Khalil, N. Chaouki, S. Cherqaoui, F. Lahmouz, and J.E. Srairi. 2000. Prevalence of the main cardiovascular risk factors in Morocco: results of a National Survey 2000. J Hypertens 21: 897-903.

[40]. WHO Atlas.2012. Global Health Expenditure Atlas. World Health Organisation

[41]. WHO Cost. 2012. The cost of diabetes.http://www.who.int/mediacentre/ factsheets/fs236/en/

[42]. Zaoui, S., C. Biémont, and K. Meguenni. 2007. Approche épidémiologique du diabète en milieux urbain et rural dans la région de Tlemcen (Ouest algérien). Cahiers Santé 17(1): 15-21.

** Supplementry Attached (Annexure 1) 